\title{
Antitumor effect of combination of S-1 and docetaxel on the human breast cancer xenograft transplanted into SCID mice
}

\author{
AKIHIKO SUTO ${ }^{1,2}$, TETSURO KUBOTA ${ }^{1,4}$, MASAKAZU FUKUSHIMA $^{3}$, \\ TADASHI IKEDA $^{1}$, TOSHIO TAKESHITA ${ }^{2}$, HARUMI OHMIYA ${ }^{2}$ and MASAKI KITAJIMA ${ }^{1}$ \\ ${ }^{1}$ Department of Surgery, School of Medicine, Keio University, Shinanomachi 35, Shinjuku-ku, Tokyo 160-8582; \\ ${ }^{2}$ Department of Surgery, Yamato Municipal Hospital, 8-3-6 Fukami-nishi, Yamato City, Kanagawa 242-8602; \\ ${ }^{3}$ Cancer Research Laboratory, Taiho Pharmaceutical Co. Ltd., 1-27 Misugidai, Hanno-city, Saitama 357-8527, Japan
}

Received December 29, 2005; Accepted February 9, 2006

\begin{abstract}
In vivo experiments were performed on breast cancer xenografts to examine whether the combination therapy with S-1, an oral dihydrouracil dehydrogenase (DPD) inhibitory fluoropyrimidine, plus docetaxel functions as an additive/synergistic modulator in tumor growth. The human breast cancer xenograft, MDA-MB-435SHM, was inoculated into SCID female mice. The tumor growth and thymidylate synthase (TS)/DPD activity of tumors treated with the agents were investigated. The $\mathrm{T} / \mathrm{C}$ value (relative mean tumor weight of the treated group/relative tumor weight of the control group) of the group treated with docetaxel, S-1 and combination therapy were 45.3, 63.1 and $29.8 \%$, respectively; suggesting the positive antitumor effects of the combination therapy in particular. In addition, significant down-regulation of DPD activity was also observed in the tumors treated with S-1, docetaxel and their combination. Down-regulation of the DPD activity of the tumors is also considered to be correlated with the antitumor effect of the treated groups, suggesting its influence on the synergistic effect of the combination therapy.
\end{abstract}

Correspondence to: Dr Akihiko Suto, Department of Surgery Yamato Municipal Hospital, 8-3-6 Fukami-nishi, Yamato City Kanagawa 242-8602, Japan

E-mail: akihiko.sutou@city.yamato.lg.jp

Present address: ${ }^{4}$ Center for Comprehensive and Advanced Medicine, Keio University Hospital, Shinanomachi 35, Shinjuku-ku, Tokyo 160-8582, Japan

Abbreviations: $\mathrm{MBC}$, metastatic breast cancer; SCID, severe combined immune-deficient; DPD, dihydropyrimidine dehydrogenase; TS, thymidylate synthase; RR, response rate; 5-FU, 5fluorouracil

Key words: breast cancer, combination therapy, S-1, docetaxel, DPD-inhibitory fluoropyrimidine

\section{Introduction}

Adjuvant chemotherapy and/or hormone therapy clearly improve the survival of breast cancer patients $(1,2)$. Metastatic breast cancer (MBC), however, demonstrates resistance against the present therapeutic procedure. Thus, new protocols with chemotherapy play a very important role in the treatment or control of advanced breast cancer. Clinical reports have demonstrated the clinical role of new agents, such as taxanes and/or oral fluoropyrimidines, especially for metastatic sites (3-7). Docetaxel, a semi-synthetic taxane and convincing agent against breast cancer $(8,9)$, acts as a potent anti-mitotic agent by the promotion of abnormal microtubule stabilization (10). Clinical studies of single-agent docetaxel treatment in MBC patients with prior anthracycline treatment have been reported demonstrating higher response rates (RR) (11-13). The results of these studies also revealed that patients who received single-agent docetaxel achieved significantly RR superior to other combination regimens, including mitomycin $\mathrm{C}$ plus vinblastine, methotrexate plus 5-fluorouracil (5-FU) and 5FU plus vinorelbine. In addition, the administration of oral fluoropyrimidines, such as capecitabine, also revealed subtle clinical responses for $\operatorname{MBC}(14,15)$.

S-1, a newly developed oral dihydropyrimidine dehydrogenase (DPD) inhibitory fluoropyrimidine drug, consisting of tegafur (FT), 5-chloro-2,4-dihydroxypyrimidine (gimeracil) and potassium oxonate (oteracil) at a molar ratio of 1:0.4:1 was reported to be a promising agent for gastric and breast cancers in phase II registration studies $(4,6)$. A recent clinical study also suggested the effectiveness of the combination regimen with S-1 and docetaxel for advanced/recurrent gastric cancer (7). The combination with S-1 and docetaxel is, therefore, expected to be an effective regimen for anthracycline and/or taxane pre-treated MBC.

The mechanism of action of the combination therapy with fluoropyrimidine and taxanes, however, has not been fully explored. In vivo experiments were designed to measure the extent of tumor growth of MDA-MB-435SHM, a human breast cancer xenograft, treated with $\mathrm{S}-1$, docetaxel and their combination. The experiments also measured the modulation of the thymidylate synthase (TS) and DPD activities of the xenograft treated with chemotherapy, in order to investigate 
the relationship between 5-FU-related biochemical parameters and tumor suppression.

\section{Materials and methods}

Mice. CB17/Icr SCID mice (female, 4-week-old) were purchased from CLEA Japan, Inc., Tokyo. The mice were maintained under specific pathogen-free conditions using an Isorack system and were fed sterile food and water ad libitum in the Keio University Animal Center. Six- to eight-week-old mice weighing $>20 \mathrm{~g}$ were used for the experiments.

Xenograft. MDA-MB-435SHM was established in the Cancer Research Laboratory, Taiho Pharmaceutical Co. Ltd. (16) and was serially transplanted at the Keio University Animal Center.

Briefly, the xenograft was established from MDA-MB-435, a human breast cancer cell line purchased from American Tissue Culture Collection (ATCC). Orthothopic transplantation of the cells was performed and lung metastasis deposits obtained were excised and transplanted into the mammary fat pad of the other 6- to 8-week female mice. This was repeated 8 times, and the new xenograft, with a high potential for tumor growth and/or lung metastasis, was established and named MDA-MB-435SHM (17). This xenograft was serially transplanted into SCID mice and used for the subsequent experiments.

Chemicals. S-1 was prepared in our laboratory by mixing tegafur, gimeracil and oteracil in a molar ratio of 1:0.4:1 in $0.5 \%$ hydroxypropyl methylcellulose. Docetaxel (Taxotere ${ }^{\circledR}$ ) was purchased from Aventis Pharma Ltd, Tokyo, Japan. $\left[6-{ }^{14} \mathrm{C}\right]-5-\mathrm{FU}(56 \mathrm{mCi} / \mathrm{mmol})$ and $\left[6-{ }^{3} \mathrm{H}\right]-\mathrm{FdUMP}(625$ $\mathrm{GBq} / \mathrm{mmol}$ ) were obtained from American Radiolabeled Chemicals Inc. (MO, USA) and Moravek Biochemicals Inc. (CA, USA), respectively.

Tumor inoculation. The tumor tissue was minced and one or two tissue fragments of the xenograft $(\sim 3 \times 3 \mathrm{~mm})$ were aseptically prepared for the inoculation. The tissue fragment was subcutaneously transplanted into the dorsum of etheranesthetized SCID mice using a trocar needle. Two fragments per mouse were inoculated separately into the dorsum to form two tumors. The transplanted tumors were measured (length and width) with sliding calipers 3 times weekly by the same observer and the tumor weight was calculated from the measurements obtained, using the formula (18):

Tumor weight $(\mathrm{mg})=$ length $(\mathrm{mm}) \mathrm{X}[\text { width }(\mathrm{mm})]^{2} / 2$.

The mice were randomized into 4 groups (control and test groups) when the estimated tumor weight reached $\sim 100-300 \mathrm{mg}$. The growth curves were generated by plotting the mean tumor weight (mg) against the treatment duration (days).

Treatment. The mice were stratified into 4 groups of 5 mice each, including: 1) control (no treatment), 2) docetaxel monotherapy, 3) S-1 monotherapy, 4) combination of S-1 and docetaxel. Docetaxel was prepared using appended solvent and the maximum tolerated dose of docetaxel $(25 \mathrm{mg} / \mathrm{kg})$ was administered intravenously on days $0,7,14$ and 21 . The

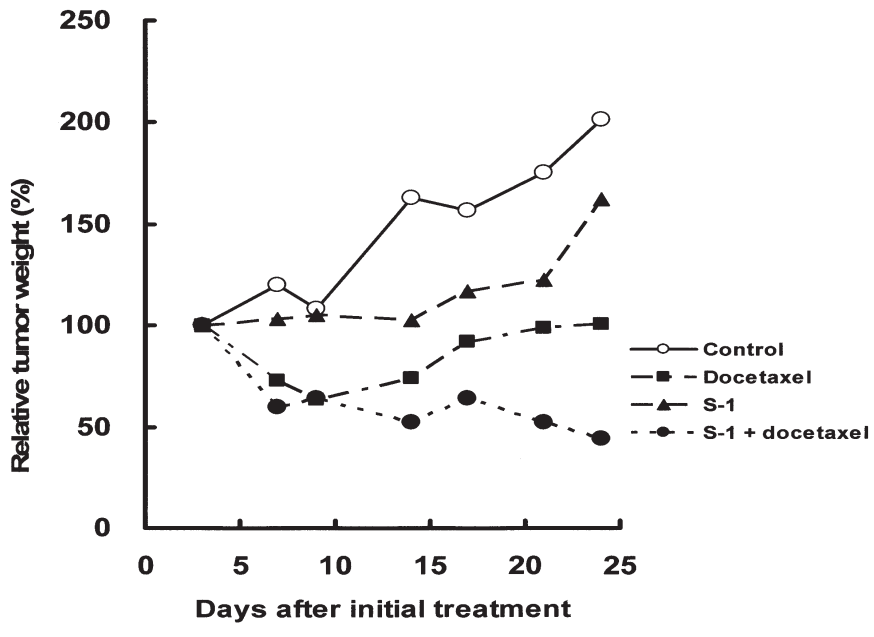

Figure 1. Antitumor activity of the agents against the growth of the xenograft. Treatment with docetaxel alone and with in S-1 showed substantial growth inhibition, while treatment with S-1 demonstrated modest change in tumor growth. Values are the mean of relative tumor weights. $\bullet$, control; घ, docetaxel alone; $\mathbf{\wedge}, \mathrm{S}-1$ alone; $\bullet$, combination with docetaxel plus S-1.

administration of S-1 was completed with the effective dose $(8.3 \mathrm{mg} / \mathrm{kg})$ orally once daily on day $0-4,7-11,14-18$ and 21-25. The schedule showed above was performed according to previously used regimens (16), and the administration schedule is derived from a clinical schedule previously reported $(19,20)$.

Evaluation. The effects of the agents on the tumor-growth curve were evaluated in terms of the lowest T/C value (\%) during the experiment, where $\mathrm{T}$ is the relative mean tumor weight of the treated group and $\mathrm{C}$ the relative tumor weight of the control group at any given time. The growth kinetic antitumor activity was evaluated as positive when the lowest $\mathrm{T} / \mathrm{C}$ was $<42 \%$, which was calculated from $(0.75)^{3}$, corresponding to a $25 \%$ reduction of each diameter.

The mice were sacrificed on day 28 after the initial treatment. The spleen was excised and weighed to investigate any adverse effect of the agent. The inoculated tumors were also excised and the effect of the agents on their tumor growth was evaluated in terms of the $\mathrm{T} / \mathrm{C}$ value $(\%)$, where $\mathrm{T}$ is the actual tumor weight of the treated group and $\mathrm{C}$ the actual tumor weight of the control.

Assays of enzyme activity. The TS and DPD activities of the tumors were also investigated using radio-assay, as described $(21,22)$.

Briefly, the tumors resected from the mouse dorsum were thawed at $4^{\circ} \mathrm{C}$ and placed in a 4 -fold excess of $0.2 \mathrm{M}$ Tris- $\mathrm{HCl}$ buffer, $\mathrm{pH} 7.4$, containing $20 \mathrm{mM}$ 2-mercaptoethanol and the phosphatase inhibitor cytidylate $(15 \mathrm{mM})$ and $\mathrm{NaF}(100 \mathrm{mM})$. The tissues were disrupted by use of a ground-glass hand homogenizer. Aliquots of the crude sonicates were removed for $105,000 \mathrm{x} g$ centrifugation and for the TS assay, the cytosol supernatant $(175 \mu \mathrm{l}), 1 \mathrm{M}$ acetic acid extraction of nucleotides (300 $\mu 1)$ were added. The TS levels were assayed by the addition of $6 \mathrm{pmol}$ of $\left[6-{ }^{3} \mathrm{H}\right] \mathrm{FdUMP}(18 \mathrm{Ci} / \mathrm{mmol})$ in $50 \mu \mathrm{l}$ of $5 \mathrm{mM}$ potassium phosphate buffer, $\mathrm{pH} 7.4$, plus $25 \mu \mathrm{l}$ of 
Table I. Growth kinetics with the NCI protocol and actual tumor weight.

\begin{tabular}{|c|c|c|c|c|c|}
\hline & $\mathrm{T} / \mathrm{C}(\%)^{\mathrm{a}}$ & On day & Mean $\pm \mathrm{SD}(\mathrm{mg})^{\mathrm{c}}$ & $\mathrm{T} / \mathrm{C}(\%)^{\mathrm{c}}$ & p-value \\
\hline Control & & & $2908 \pm 537$ & 100 & \\
\hline Docetaxel & 45.3 & 14 & $1268 \pm 724$ & 43.6 & $<0.001$ \\
\hline S-1 & 63.1 & 14 & $2938 \pm 833$ & 101 & NS \\
\hline Docetaxel + S-1 & $29.8^{b}$ & 21 & $407 \pm 624$ & 13.9 & $<0.001$ \\
\hline
\end{tabular}

${ }^{a} \mathrm{NCI}$ protocol with tumor growth; $\mathrm{T} / \mathrm{C}=$ minimum, $\mathrm{T}$ relative weight/C relative weight. ${ }^{\mathrm{b}}$ Positive effect for antitumor activity, ${ }^{\mathrm{c}} \mathrm{data}$ are derived from actual tumor weights.

Table II. Enzyme activities of the xenografts.

\begin{tabular}{lcccc}
\hline & DPD & p-value & TS & p-value \\
\hline Control & $462.03 \pm 83.8^{\mathrm{a}}$ & & $26.6 \pm 8.0^{\mathrm{b}}$ & \\
Docetaxel & $349.33 \pm 95.5$ & $<0.05$ & $25.3 \pm 5.0$ & $\mathrm{NS}$ \\
S-1 & $256.44 \pm 97.9$ & $<0.05$ & $37.1 \pm 12.0$ & $\mathrm{NS}$ \\
Docetaxel $+\mathrm{S}-1$ & $198.41 \pm 172.8$ & $<0.05$ & $20.5 \pm 9.0$ & $\mathrm{NS}$ \\
\hline
\end{tabular}

${ }^{\mathrm{a}} \mathrm{pmol} / \mathrm{min} / \mathrm{mg}$ protein; ${ }^{\mathrm{b}} \mathrm{fmol} / \mathrm{min} / \mathrm{mg}$ protein; ${ }^{\mathrm{c}} \mathrm{p}$-value vs. control. DPD, dihydropyrimidine dehydrogenase; TS, thymidylate synthase. Statistical analysis of DPD activities between docetaxel and combination, S-1, and combination revealed no significant change, NS.

cofactor solution. The results are shown as bound contents of $\left[{ }^{3} \mathrm{H}\right] \mathrm{FdUMP}$ to TS via reduced folate to TS. The DPD activity was determined as the sum of the degeneration products from $\left[6-{ }^{14} \mathrm{C}\right]-5-\mathrm{FU}$ by a modification of the method of Naguib et al (22).

Statistical analysis. The statistical analysis was performed using the Student's t-test and the Chi-square test. $\mathrm{p}<0.05$ was considered to be significant.

\section{Results}

The growth kinetics of the MDA-MB-435SHM xenotransplants are presented in Fig. 1. The treatment with docetaxel alone and the combination with docetaxel plus S-1 resulted in substantial growth inhibition, while the treatment with S-1 demonstrated only a modest change in the growth of the MDA-MB-435SHM xenografts. The in vivo growth modulation of the tumors was also assessed by determining the $\% \mathrm{~T} / \mathrm{C}$ values of growth kinetics after treatment with $\mathrm{S}-1$, docetaxel and their combination (Table I). In the recipients treated with docetaxel, S-1 and their combination, the T/C values decreased by $45.3,63.1$ and $29.8 \%$, respectively. In the recipients treated with a combination of the two agents, a significant suppression of tumor growth with a T/C value $<42 \%$ was observed. A comparison of the $\mathrm{T} / \mathrm{C}$ ratio derived from the actual tumor weight, assessed by resection of the tumor xenograft also indicated the advantage of combination therapy (Table I). In the recipients receiving docetaxel alone or a combination of the two agents, the $\mathrm{T} / \mathrm{C}$ values decreased by $43.6 \%(p<0.001)$ and $13.9 \%(p<0.001)$, respectively; while in the recipients receiving $\mathrm{S}-1$ monotherapy, the T/C value was not significantly different from those of the control. Furthermore, the product of T/C values of the two monotherapy groups equals $44 \%$ $(0.436 \times 1.01)$, which is greater than that of combinationtreated group (13.9\%). Since S-1 showed no inhibitory effect in terms of the weight of the xenograft, the combination therapy can be considered to synergistically affect the tumor growth property.

The DPD activities in the control, docetaxel-treated, TS1 -treated and combination-treated tumors were 462.03, $349.33,256.44$ and $198.41 \mathrm{pmol} / \mathrm{min} / \mathrm{mg} /$ protein, respectively (Table II). These results indicate a significant down-regulation of tumor DPD activity by these agents. In particular, the tumors treated with the combination demonstrated an inhibition of DPD activity. However, the TS activities of the xenografts were not significantly changed from control after any of the treatments (Table II).

Adverse effects of the agents were shown only in the combination group (Table III). The total body and excised spleen weight gain of the recipients from the combinationtreated group differed by $>5 \%$ of that of control, indicating moderate treatment-related toxicity. In addition, one mouse 
Table III. Adverse effects on body weight and actual spleen weight.

\begin{tabular}{|c|c|c|c|c|c|c|}
\hline & $\begin{array}{c}\text { Day } 3 \\
\text { weight in } g\end{array}$ & $\begin{array}{c}\text { Day } 7 \\
\text { weight in } g\end{array}$ & $\begin{array}{c}\text { Day } 14 \\
\text { weight in } g\end{array}$ & $\begin{array}{c}\text { Day } 21 \\
\text { weight in } g\end{array}$ & Mean $\pm \mathrm{SD}^{\mathrm{b}}$ & p-value \\
\hline Control & 22.8 & $\begin{array}{c}24.0 \\
(\triangle 5.2 \%)^{\mathrm{a}}\end{array}$ & $\begin{array}{c}25.8 \\
(\triangle 13.1 \%)\end{array}$ & $\begin{array}{c}26.4 \\
(\triangle 15.7 \%)\end{array}$ & $186 \pm 28.8$ & \\
\hline Docetaxel & 21.2 & 21.2 & $\begin{array}{c}22.2 \\
(\triangle 4.7 \%)\end{array}$ & $\begin{array}{c}22.5 \\
(\triangle 6.1 \%)\end{array}$ & $150 \pm 46.9$ & NS \\
\hline S-1 & 22.2 & $\begin{array}{c}23.2 \\
(\triangle 4.5 \%)\end{array}$ & $\begin{array}{c}24.2 \\
(\triangle 9.0 \%)\end{array}$ & $\begin{array}{c}24.2 \\
(\triangle 9.0 \%)\end{array}$ & $186 \pm 45.0$ & NS \\
\hline Docetaxel + S-1 & 21.5 & $\begin{array}{c}20.2 \\
(\nabla 6.0 \%)^{\mathrm{a}}\end{array}$ & $\begin{array}{c}18.5 \\
(\nabla 13.9 \%)\end{array}$ & $\begin{array}{c}19.7 \\
(\nabla 8.3 \%)\end{array}$ & $140 \pm 34.6$ & $<0.05$ \\
\hline
\end{tabular}

${ }^{\mathrm{a}} \triangle$, percent volume of weight increase; $\mathbf{\nabla}$, percent volume of weight gain. ${ }^{\mathrm{b}}$ Actual spleen weight $(\mathrm{mg}),{ }^{\mathrm{c}}$ spleen weight $\mathrm{p}$-value vs. control.

treated with combination died on day 24 after the initial treatment.

\section{Discussion}

This study was aimed at clarifying whether the combination therapy with S-1 and docetaxel is effective for the treatment of breast cancer, using the in vivo SCID mouse system as a model. Docetaxel, a potent antitumor agent, has been widely used, and the clinical advantage for breast cancer patients has also been fully confirmed (8-10). In addition, recent clinical reports focused on the efficacy of the docetaxel and oral fluoropyrimidine combination $(3,7)$. Of the selected test compounds, S-1, a new oral fluoropyrimidine, demonstrates both potent anti-metabolite and DPD-inhibiting properties due to the effects of tegafur and gimeracil, respectively. DPD, a catabolizing enzyme of 5-FU has been demonstrated to play an important role in the antitumor effect against several solid tumor types (23). The results of our previous study also suggest that the combination with S-1 and paclitaxel has potently higher antitumor, and antimetastatic properties in vivo (16). A clinical study of S-1 plus docetaxel combination therapy with breast cancer patients has not been assessed to date.

For gastric cancer in Japan, the clinical investigation of the combination of S-1 and docetaxel was reported for a Phase I registration study, showing a significant effect of the metastatic site, with a response rate (RR) of $71.4 \%$ (7). This RR is significantly higher than that of S-1 and docetaxelmonotherapy (40 and 20\%, respectively) (24-29). The data shown above suggest that the combination of S-1 and docetaxel has a promising property for the treatment of pre-treated metastases. In addition, the RR of docetaxel-monotherapy in $\mathrm{MBC}$ is reported to be 55.3-67.7\% (30), indicating higher RR than for gastric cancer.

The kinetic curve for the combination with S-1 and docetaxel (Fig. 1) clearly demonstrates that the combination of the 2 tumor-suppressing agents is effective in suppressing the tumor growth. The $\mathrm{T} / \mathrm{C}$ ratio derived from tumor growth kinetics also decreased especially in the combination group. These in vivo observations corroborate those reported by
Nukatsuka et al (16), and, therefore, demonstrate significant antitumor advantage of treatment with $\mathrm{S}-1$ and taxanes. It is also clear from the data presented in Table I that the combination of 2 tumor-suppressing agents strongly affects the actual tumor weight, compared to that of monotherapy groups.

The administration of $\mathrm{S}-1$, with the maximum tolerated dose, demonstrated no inhibitory effect for tumor growth. Although the reason for this lack of tumor suppression is unclear, it is well known that the distribution volume related to the 5-FU metabolic pathway is very small in the nude mouse (athymic mouse) system (31); thus, a similar distribution may be observed in the degeneration of S-1 in SCID mice. Takahashi et al reported that 5-FU plasma levels in rats did not change by the simultaneous intravenous administration of docetaxel with oral S-1 (32). Since the tumoral drug concentration of 5-FU after administration of S-1 is closely related to plasma drug concentration, the 5-FU levels in breast tumors used in this study were considered to be almost similar between $\mathrm{S}-1$ alone and S-1 combined with docetaxel.

The induction of the suppression of tumor weight in this experiment, however, was derived from the combination with moderately effective and ineffective agents. The effects of the individual agents on tumor growth, taken together with the moderate and ineffective agents, suggest that the observed anti-proliferative activity may be synergistic. The synergistic effect of the 5-FU and docetaxel combination has been already reported using mouse mammary epithelial cells both in vitro and in vivo (33). However, the mechanism of synergism of these compounds is not fully understood. 5-FU affects the 'arrest' of cell proliferation by blocking the $\mathrm{G} 2$ and $\mathrm{S}$ phases of the cell cycle. In addition, the G2/M phase is affected by taxanes. With the manifestation of different mechanisms of action of the individual agents, an additive (not synergistic) modulation might be expected when combination therapy is implemented.

The adverse effects of the experimental therapies were observed and considered to be similar with those of clinical studies (7). The spleen and body weight loss of mice during the experiments may indicate hematological and nonhematological toxicities. 
The DPD activity of primary breast cancers has been reported to be higher than in other cancers (34). In addition, the DPD activity in metastatic tumors has been reported to be higher than that of primary tumors or normal tissue in colorectal and breast cancer patients $(35,36)$. In the in vivo mouse system, however, the tumor xenograft DPD activity is generally lower than that of clinical tumors (37). The MDA-MB435SHM xenograft used for our experiment, has been confirmed to have higher DPD activity than other human tumor xenografts (16). The results of the enzyme activity assay (Table II) clearly demonstrate that the tumor-suppressing agents are effective for down-regulation of DPD, while no significant enhancement in terms of TS activity was observed. It is interesting to note that the modulation of tumor growth in vivo strongly correlated with a similar modulation (downregulation) of DPD activity. It is also noteworthy that the combination treatment caused the greatest down-regulation of DPD activity. Unlike S-1, docetaxel is not a DPD-inhibitory compound, and thus, would not be expected to affect a significant influence on DPD activity. DPD alteration in malignant tumors induced by docetaxel has not been previously reported, with the exception of one report of the investigation of the induction of DPD expression by docetaxel in gastric cancer. However, the data resulted in no induction of DPD expression (38). Our results regarding DPD activity, however, demonstrate a significant down-regulation upon the administration of docetaxel. Thus, the modulation seen in the combination of S-1 and docetaxel on DPD activity is largely dependent upon the additive reaction led by two individual DPD-inhibitory agents. Therefore, it is conceivable that synergistic growth regulation of xenotransplanted breast cancer by the combination of S-1 and docetaxel may be a manifestation of the combined strong down-regulation of DPD activity. The synergistic effect of combination therapy on tumor growth may partly be due to the additive DPD inhibition.

In conclusion, the present study on breast cancer xenografts has shown that tumor growth kinetics and DPD activity of the tumor can be down-regulated by agents that are known to suppress tumor growth in clinical studies. The down-regulation of DPD activity of tumor cells might be a key parameter in tumor suppression. Although adverse effects are present, the combination of S-1 and docetaxel is a promising candidate in the treatment of MBC.

\section{References}

1. Mansour EG, Gray R, Shatila AH, Tormey DC, Cooper MR, Osborne CK and Falkson G: Survival advantage of adjuvant chemotherapy in high-risk node-negative breast cancer: tenyear analysis - an intergroup study. J Clin Oncol 16: 3486-3492, 1998.

2. Goldhirsch A, Glick JH, Gelber RD and Seen HJ: Meeting highlights: International consensus panel on the treatment of primary breast cancer. J Natl Cancer Inst 90: 1601-1608, 1998.

3. O'Shaughnessy J, Miles D, Vukelja S, Maiseyenko V, Ayoub JP, Cervantes G, Fumoleau P, Jones S, Lui WY, Mauriac L, Twelves C, Hazel GV, Verma S and Leonard R: Superior survival with capecitabine plus docetaxel combination therapy in anthracycline-pretreated patients with advanced breast cancer: phase III trials results. J Clin Oncol 20: 2812-2823, 2002.

4. Nagashima F, Ohtsu A, Yoshida S and Ito K: Japanese nationwide post-marketing survey of S-1 in patients with advanced gastric cancer. Gastric Cancer 8: 6-11, 2005.
5. Schöffski P: The modulated oral fluoropyrimidine prodrug S-1, and its use in gastrointestinal cancer and other solid tumors. Anticancer Drugs 15: 85-106, 2004.

6. Saeki T, Takashima S, Sano M, Horikoshi N, Miura S, Shimizu S, Morimoto K, Kimura M, Aoyama H, Ota J, Noguchi S and Taguchi T: A phase II study of S-1 in patients with metastatic breast cancer - a Japanese trial by the S-1 cooperative study group, breast cancer working group. Breast Cancer 11: 194-202, 2004.

7. Yoshida K, Hirabayashi N, Takiyama W, Ninomiya M, Takakura N, Sakamoto J, Nishiyama M and Toge T: Phase I study of combination therapy with S-1 and docetaxel (TXT) for advanced or recurrent gastric cancer. Anticancer Res 24: 1843-1852, 2004.

8. O'Brien ME, Leonard RC, Barrett-Lee PJ, Eggleton SP and Bizzari JP: Docetaxel in the community setting: an analysis of 377 breast cancer patients treated with docetaxel (Taxotere) in the UK. UK Study Group. Ann Oncol 10: 205-210, 1999.

9. Kouroussis C, Androulakis N, Kakolyris S, Souglakos J, Kotsakis T, Mavroudis D, Katsogridakis K, Vardakis N, Hatzidaki D, Samonis G, Vlachonikolis J and Georgoulias V: Dose-escalation study of docetaxel in combination with mitoxantrone as first-line treatment in patients with metastatic breast cancer. J Clin Oncol 17: 862-869, 1999.

10. Ravdin PM, Burris HA, Cook G, Eisenberg P, Kane M, Bierman WA, Mortimer J, Genevois E and Bellet RE: Phase II trial of docetaxel in advanced anthracycline-resistant or anthracenedione-resistant breast cancer. J Clin Oncol 13: 2879-2885, 1995.

11. Nabholtz JM, Senn HJ, Bezwoda WR, Melnychuk D, Deschênes L, Douma J, Vandenberg TA, Rapoport B, Rosso R, Trillet-Lenoir V, Drbal J, Molino A, Nortier JWR, Richel DJ, Nagykalnai T, Siedlecki P, Wilking N, Genot JY, Hupperets PSGJ, Pannuti F, Skarlos D, Tomiak EM, Murawsky M, Alakl M, Riva A, Aapro M and 304 Study Group: Prospective randomized trial of docetaxel versus mitomycin plus vinblastine in patients with metastatic breast cancer progressing despite previous anthracycline-containing chemotherapy. 304 Study Group. J Clin Oncol 17: 1413-1424, 1999.

12. Sjöström J, Blomqvist C, Mouridsen H, Pluzanska A, OttossonLonn S, Bengtsson NO, Ostenstad B, Mjaaland I, Palm-Sjovall M, Wist E, Valvere V, Anderson H and Bergh J: Docetaxel compared with sequential methotrexate and 5-fluorouracil in patients with advanced breast cancer after anthracycline failure: a randomized phase III study with crossover on progression by the Scandinavian Breast Group. Eur J Cancer 35: 1194-1201, 1999.

13. Bonneterre J, Roche H, Monnier A, Guastalla JP, Namer M, Fargeot P and Assadourian S: Docetaxel vs. 5-fluorouracil plus vinorelbine in metastatic breast cancer after anthracycline therapy failure. Br J Cancer 87: 1210-1215, 2002.

14. Blum JL, Jones SE, Buzdar AU, LoRusso PM, Kuter I, Vogel C, Osterwalder B, Burger HU, Brown CS and Griffin T: Multicenter phase II study of capecitabine in paclitaxel-refractory metastatic breast cancer. J Clin Oncol 17: 485-493, 1999.

15. Blum JL, Dieras V, Lo Russo PM, Horton J, Rutman O, Buzdar A and Osterwalder B: Multicenter phase II study of capecitabine in taxane-pretreated metastatic breast carcinoma. Cancer 92: 1759-1768, 2001.

16. Nukatsuka M, Fujioka A, Nakagawa F, Oshimo H, Kitazato K, Uchida J, Sugimoto Y, Nagayama S and Fukushima M: Antimetastatic and anticancer activity of S-1, a new oral dihydropyrimidine-dehydrogenase-inhibiting fluoropyrimidine, alone and in combination with paclitaxel in an orthotopically implanted human breast cancer model. Int J Oncol 25: 1531-1536, 2004.

17. Nukatsuka M, Fujioka A, Nakagawa F and Fukushima M: Antimetastatic and antitumor effects of fluoropyrimidines alone and combined with taxanes in murine model of breast cancer metastatic to the lung. Jpn J Cancer Chemother 29: 95-101, 2002 (In Japanese).

18. Geran RI, Greenberg NH, Schumacher AM and Abbott BJ: Protocols for screening chemical agents and natural products against animal tumors and other biological systems (third edition). Cancer Chemother Rep 3: 51-61, 1972.

19. Fukushima M, Satake H, Uchida J, Shimosato Y, Kato T, Takechi T, Okabe H, Fujioka A, Nakano K, Ohshimo H, Takeda S and Shirasaka T: Preclinical antitumor efficacy of S-1: a new oral formulation of 5-fluorouracil on human tumor xenografts Int J Oncol 13: 693-698, 1998. 
20. Ouch-Fujimoto K, Tanaka Y and Tominaga T: Schedule dependency of antitumor activity in combination therapy with capecitabine/5'-deoxy-5-fluorouridine and docetaxel in breast cancer models. Clin Cancer Res 7: 1079-1086, 2001.

21. Spears CP, Shahinian AH, Moran RG, Heidelberg C and Corbett TH: In vitro kinetics of thymidylate synthase inhibition in 5-fluorouracil-sensitive and resistant murine colon adenocarcinomas. Cancer Res 42: 450-456, 1982.

22. Naguib FNM, El-Kouni MH and Cha S: Enzymes of uracil catabolism in normal and neoplastic human tissues. Cancer Res 45: 5405-5412, 1985.

23. Takechi T, Uchida J, Fujioka A and Fukushima M: Enhancing 5-fluorouracil cytotoxicity by inhibiting dihydropyrimidine dehydrogenase activity with uracil in human tumor cells. Int J Oncol 11: 1041-1044, 1997.

24. Sakata Y, Ohtsu A, Horikoshi N, Sugimachi K, Mitachi Y and Taguchi T: Late phase II study of novel oral fluoropyrimidine anticancer drug S-1 (1 M tegafur- $0.4 \mathrm{M}$ gimestat-1 M otastat potassium) in advanced gastric cancer patients. Eur J Cancer 34: 1715-1720, 1998.

25. Koizumi W, Kurihara M, Nakano S and Hasegawa K: Phase II study of S-1, a novel oral derivative of 5-fluorouracil, in advanced gastric cancer. Oncology 58: 191-197, 2000.

26. Taguchi T, Sakata Y, Kanamaru R, Kurihara M, Suminaga M, Ota J and Hirabayashi N: Late phase II clinical study of RP56976 (Docetaxel) in patients with advanced/recurrent gastric cancer: A Japanese cooperative study group trial(Group A). Jpn J Cancer Chemother 25: 1915-1924, 1998 (In Japanese).

27. Mai M, Sakata Y, Kanamaru R, Kurihara M, Suminaga M, Ota J, Hirabayashi N, Taguchi T and Furue H: A late phase II clinical study of RP56976 (Docetaxel) in patients with advanced or recurrent gastric cancer: a cooperative study group trial (Group B). Jpn J Cancer Chemother 26: 487-496, 1999 (In Japanese).

28. Sulkes A, Smyth J, Sessa C, Dirix LY, Vermorken JB, Kaye S, Wanders KJ, Franklin H, LeBail N and Verwij J for the EPRTC Clinical Trial Group: Docetaxel (Taxotere) in advanced gastric cancer: results of a phase II clinical trial. Br J Cancer 70: 380-383, 1994.

29. Yamada Y, Shirao K, Ohtsu A, Boku N, Hyodo I, Saitoh H, Miyata Y and Taguchi T: Phase II trial of paclitaxel by three-hour infusion for advanced gastric cancer with short premedication for prophylaxis against paclitaxel-associated hypersensitivity reaction. Ann Oncol 12: 1133-1137, 2001.
30. Trudeau ME: Docetaxel (Taxotere): an overview of first-line monotherapy. Semin Oncol 22: 17-21, 1995.

31. Isobe Y, Kubota T, Asanuma F, Kurihara H, Inada T, Fukutomi T, Ishibiki $\mathrm{K}$ and Abe O: Pharmacodynamic aspects of in vitro and in vivo chemosensitivity tests. Jpn J Cancer Res 78: 983-990, 1987.

32. Takahashi I, Emi Y, Kakeji Y, Uchida J, Fukushima M and Maehara Y: Increased antitumor activity in combined treatment TS-1 and docetaxel: a preclinical study using gastric cancer xenografts. Oncology 68: 130-137, 2005.

33. Takeda Y, Yoshizaki I, Nonaka Y, Yanagie H, Matsuzawa A and Eriguchi M: Docetaxel alone or orally combined with 5fluorouracil and its derivatives: effects on mouse mammary tumor cell line MM2 in vitro and in vivo. Anticancer Drugs 12: 691-698, 2001.

34. Mori K, Hasegawa M, Nishida M, Toma H, Fukuda M, Kubota T, Nagasue N, Yamana H, Hirakawa-YS, Chung K, Ikeda T, Takasaki K, Oka M, Kameyama M, Toi M, Fujii H, Kitamura M, Murai M, Sasaki H, Ozono S, Makuuchi H, Shimada Y, Onishi Y, Aoyagi S, Mizutani K, Ogawa M, Nakao A, Kinoshita H, Tono T, Imamoto H, Nakashima Y and Manabe T: Expression levels of thymidine phosphorylase and dihydropyrimidine dehydrogenase in various human tumor tissues. Int $\mathbf{J}$ Oncol 17: 33-38, 2000.

35. Ikeguchi M, Hirooka Y, Makino M and Kaibara N: Dihydropyrimidine dehydrogenase activity of cancerous and noncancerous tissues in liver and large intestine. Oncol Rep 8: 621-625, 2001.

36. Anan K, Mitsuyama S, Tamae K, Suehara N, Nishihara K, Ogawa Y, Abe Y, Iwashita T and Toyoshima S: Increased dihydropyrimidine dehydrogenase activity in breast cancer. J Surg Oncol 82: 174-179, 2003.

37. Ishikawa Y, Kubota T, Otani Y, Watanabe M, Teramoto T, Kumai K, Takechi T, Okabe H, Fukushima M and Kitajima M: Dihydropyrimidine dehydrogenase and messenger RNA levels in gastric cancer: possible predictor for sensitivity to 5-fluorouracil. Jpn J Cancer Res 91: 105-112, 2000.

38. Okitsu H, Umemoto A, Honda J, Okitsu N, Seike J, Tanida N and Monden Y: Induction of TP and DPD expression by docetaxel and doxifluridine (5'-DFUR) in gastric cancer. Nippon Rinsyo Gekagakkai-shi 65: 587-593, 2004 (In Japanese). 